\title{
Evidence that Spt4, Spt5, and Spt6 control transcription elongation by RNA polymerase II in Saccharomyces cerevisiae
}

\author{
Grant A. Hartzog ${ }^{1}$ Tadashi Wada, $^{2}$ Hiroshi Handa, ${ }^{2}$ and Fred Winston ${ }^{1,3}$ \\ ${ }^{1}$ Department of Genetics, Harvard Medical School, Boston, Massachusetts 02115 USA; ${ }^{2}$ Faculty of Bioscience and \\ Biotechnology, Tokyo Institute of Technology, Yokohama 226, Japan
}

\begin{abstract}
Previous characterization of the Saccharomyces cerevisiae Spt4, Spt5, and Spt6 proteins suggested that these proteins act as transcription factors that modify chromatin structure In this work, we report new genetic and biochemical studies of Spt4, Spt5, and Spt6 that reveal a role for these factors in transcription el ongation. We have isolated conditional mutations in SPT 5 that can be suppressed in an allele-specific manner by mutations in the two largest subunits of RNA polymerase II (Pol II). Strikingly, one of these RNA Pol II mutants is defective for transcription elongation and the others cause phenotypes consistent with an elongation defect. In addition, we show that spt4, spt5, and spt6 mutants themselves have phenotypes suggesting defects in transcription elongation in vivo. Consistent with these findings, we show that Spt5 is physically associated with RNA Pol II in vivo, and have identified a region of sequence similarity between Spt5 and NusG, an Escherichia coli transcription elongation factor that binds directly to RNA polymerase. Finally, we show that Spt4 and Spt5 are tightly associated in a complex that does not contain Spt6. These results, taken together with the biochemical identification of a human Spt4-Spt5 complex as a transcription elongation factor (Wada et al. 1998), provide strong evidence that these factors are important for transcription elongation in vivo.
\end{abstract}

[Key Words: Transcription elongation; Spt4; Spt5; Spt6; N usG; chromatin]

Received N ovember 20, 1997; revised version accepted December 8, 1997.

Transcription elongation is an important aspect of gene regulation in both prokaryotes and eukaryotes. In Escherichia col $i$ and bacteriophage $\lambda$, the cis-acting elements and trans-acting factors that regulate transcription elongation have been characterized extensively (U ptain et al . 1997). Whereas elongation is less well understood in eukaryotes, many of the factors that control this process have been identified biochemically and are now the focus of intense interest. For el ongation by RN A polymerase II (Pol II), these factors include the general transcription factors, TFIIS, TFIIH, TFIIF, and the elongins (Uptain et al. 1997), transcriptional activators such as heat shock factor (Lis and Wu 1993), and factors that affect chromatin structure, including histones, the nucleosome remodeling complex Snf-Swi (Brown et al. 1996), and the chromatin protein HMG14 (Ding et al. 1994).

$M$ any eukaryotic elongation factors function by either preventing or overcoming transcriptional pausing by RNA Pol II. In eukaryotes, this has been most carefully documented at Drosophila hsp genes in which a regulated pause occurs a short distance from the initiation

${ }^{3}$ Corresponding author.

E-MAIL winston@rascal.med.harvard.edu; FAX (617) 432-3993. site (Lis and Wu 1993), and in HIV in which the action of the virus-encoded TAT protein is required to overcome an early block to elongation (Jones 1997). Many other eukaryotic genes are known to have blocks to elongation (U ptain et al. 1997), and blocking may represent a general feature of transcription by RN A Pol II (Bentley 1995; Krumm et al. 1995). Given that pause sites can occur throughout a gene, and that nucleosomes provide a repeating barrier to el ongation, it seems likely that eukaryotes use specific mechanisms and factors to permit efficient elongation across the length of a gene (Chang and Luse 1997; Uptain et al. 1997). Such factors might be required to alter nucleosomes to permit passage of RNA Pol II, to restore normal nucleosome positioning or structure following passage of RNA Pol II, or both.

Spt4, Spt5, and Spt6 of Saccharomyces cerevisiae are conserved proteins, believed to be involved in transcription and chromatin structure. These proteins were initially identified by mutations that suppress cis- and trans-acting mutations that affect promoter function (Winston and Carlson 1992). Substantial genetic analysis has suggested that all three proteins are involved in a common function in vivo (Swanson and Winston 1992). Recent work on Spt6 has shown that it interacts with 
histones, that it can assemble nucleosomes in vitro, and that spt6 mutations alter chromatin structure in vivo (Bortvin and Winston 1996). In addition to their role in transcription, genetic studies suggest that these proteins are required for normal recombination (Malagon and Aguilera 1996) and chromosome segregation (Basrai et al . 1996), rai sing the possibility that they are involved in the establishment or maintenance of chromatin states necessary for diverse chromosomal functions.

Previ ous studies of SPT4, SPT5, and SPT 6 involved the analysis of mutant alleles isolated by particular genetic selections (Winston and Carlson 1992). Because SPT5 and SPT6 are essential for growth, these studies may have yiel ded mutations conferring only a subset of the possible mutant phenotypes that could be acquired. In this work, we have isolated new mutations in SPT5, requiring only that they cause cold-sensitive growth. Our analysis of these mutants and of extragenic suppressors has led us to evidence that Spt4, Spt5, and Spt6 are required for transcription elongation in vivo. Consistent with these genetic data, we have obtained evi dence that Spt5 associates with RN A Pol II. Finally, we show that Spt4 and Spt5 are in a complex that does not contain Spt6. These results, in conjunction with those in the accompanying manuscript (Wada et al. 1998) that show that a human Spt4-Spt5 complex affects transcription elongation in vitro, provide strong evidence that these proteins play an important role in transcription elongation throughout eukaryotes.

\section{Results}

Identification of cold-sensitive spt5 mutants

Previous genetic analysis of SPT5 relied on spt5 muta- tions that were sel ected either as suppressors of insertion mutations or as suppressors of snf-swi mutations (Winston and Carlson 1992). Because SPT5 is essential for growth, such mutations might represent a particular class of spt5 alleles and, hence, only cause a subset of possible spt5 mutant phenotypes. Therefore, we screened for a new class of spt5 mutations-those that cause cold-sensitive ( $\mathrm{Cs}^{-}$) growth. Two new spt5 mutations that cause a $\mathrm{Cs}^{-}$phenotype, spt5-242 and spt5-276, were isolated. Both mutations al so cause the phenotype observed for the original spt5 mutations, suppression of Ty $\delta$ insertion mutations (Spt ${ }^{-}$phenotype; Table 1). As shown in subsequent sections, however, these new spt5 alleles have reveal ed a previ ously unknown role for Spt5. In both spt5 $\mathrm{Cs}^{-}$mutants, the level of Spt5 protein is unaffected, even when the strains are grown at nonpermissive temperature for $48 \mathrm{hr}$ (data not shown).

To look directly at the effects of the spt5 $\mathrm{Cs}^{-}$mutations on transcription, we examined the steady-state levels of three different mRNAs by Northern hybridization analysis. The results show that the spt5 mutations cause a significantly reduced level of TPI 1 and HIS4 mRNAS when cells are shifted to the nonpermissi ve temperature $\left(13^{\circ} \mathrm{C}\right.$ ) for $48 \mathrm{hr}$ (Fig. 1). Under the conditions of this experiment, there was no loss of viability for the spt5 mutants (data not shown). These results show that the spt5 $\mathrm{Cs}^{-}$mutations cause decreased levels of some, but not all, RN A Pol II-dependent transcripts.

Extragenic suppressors in RPB1 suggest that the spt5 $\mathrm{Cs}^{-}$mutations impair transcription el ongation

To identify proteins that might interact with Spt5, we selected for suppressors of the two spt5 $\mathrm{Cs}^{-}$mutants.

Table 1. Phenotypes of spt5 $\mathrm{Cs}^{-}$and $\mathrm{rpb} 1 / \mathrm{rpo} 21$ mutants

\begin{tabular}{|c|c|c|c|c|c|}
\hline \multirow{2}{*}{$\begin{array}{l}\text { Relevant } \\
\text { genotype }\end{array}$} & \multicolumn{4}{|c|}{ Growth ${ }^{a}$} & \multirow{2}{*}{$\begin{array}{c}\text { Other } \\
\text { phenotypes }\end{array}$} \\
\hline & $15^{\circ} \mathrm{C}$ & $30^{\circ} \mathrm{C}$ & $37^{\circ} \mathrm{C}$ & $\mathrm{SC}-\mathrm{His}^{\mathrm{b}}$ & \\
\hline 1 wild type & + & + & + & - & \\
\hline 2 spt5-242 & - & $H-$ & + & $H-$ & \\
\hline 3 spt5-276 & - & $H-$ & + & $H-$ & \\
\hline 4 rpb1-221 & + & + & + & $-1+$ & $6 A U^{S}$ \\
\hline 5 rpb1-244 & + & + & + & $-1+$ & $6 A U^{5}$ \\
\hline 6 rpo21-18 & N.D. & + & + & - & $6 A U^{S}$ \\
\hline 7 rpb1-5 & $t^{c}$ & + & - & N.D. & \\
\hline $8 \mathrm{rpb} 1-244 \mathrm{spt} \mathrm{Cs}^{-d}$ & $H-$ & $H-$ & $H-$ & $H-$ & $6 A U^{S}$ \\
\hline $9 \mathrm{rpb} 1-221 \mathrm{spt} 5 \mathrm{Cs}^{\mathrm{d}^{d}}$ & $H-$ & $H-$ & $H-$ & $H-$ & $6 A U^{S}$ \\
\hline 10 rpo21-18 spt5-242 & - & $-1+$ & $H-$ & N.D. & $6 A U^{5}$ \\
\hline 11 rpb1-5 spt5-276 & - & $H-$ & - & N.D. & \\
\hline
\end{tabular}

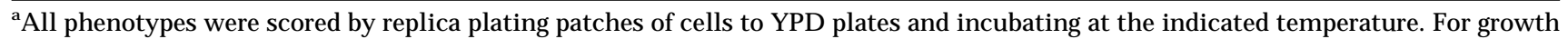
at $15^{\circ} \mathrm{C}$, +indicates confluent growth after 3 days, $+/$-indicates slightly less growth than + , and -indicates little or no growth after 5 days. For growth at $30^{\circ} \mathrm{C}$ and $37^{\circ} \mathrm{C}$, +indicates confluent growth after 1 day, +- -indicates that the strain grew nearly as well as wild type, $-1+$ indicates slow but definite growth after 3 days, and -indicates little or no growth after 3 days. (N .D.) N ot done.

bSC-His tests the Spt phenotype. Spt ${ }^{+}$strains are $\mathrm{His}^{-}$, and $\mathrm{Spt}^{-}$strains are $\mathrm{His}^{+}$(Winston et al. 1984). Growth on SC-His was scored at $30^{\circ} \mathrm{C}$. +1 -indicates confluent growth after 2 days, $-1+$ indicates slow but definite growth after 3 days, and -indicates little or no growth after 3 days.

'These data were reported in Scafe et al. (1990a).

वThe spt5 $\mathrm{Cs}^{-}$mutations suppressed the rpb1 ${ }^{\text {sup }}$ mutations indistinguishably. Therefore, lines 7 and 8 each refer to double mutant combinations of the rpb1 allele with both spt5-242 and spt5-276. 


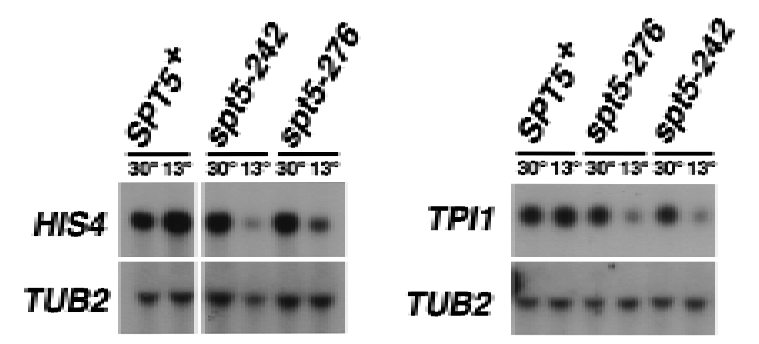

Figure 1. N orthen blot analysis of SPT5 ${ }^{+}$and spt $5 \mathrm{Cs}^{-}$strains. $\mathrm{SPT}^{+}$, spt5-242, and spt5-276 strains were grown at $30^{\circ} \mathrm{C}$ or $13^{\circ} \mathrm{C}$ for $48 \mathrm{hr}$ prior to isolation of RN A for Northern analysis. The blots were probed with HIS4 or TPI 1 as indicated, and al so with TUB2 as a normalization control. $\mathrm{N}$ ote that the order of the two mutants is different in the two experiments shown. The blot on the left contains RN A from strains FY2, FY1672, and FY 1673. The blot on the right contains RNA from strains FY120, FY1634, and FY 1635.

Interestingly, two of the suppressor mutations are in RPB1/RPO21, which encodes the largest subunit of RNA Pol II (see Materials and Methods; hereafter, we will refer to this gene and its mutant forms as RPB1, except for mutant alleles published previously as RPO 21). These suppressor mutations have been designated rpb1-221 and rpb1-244 and will be referred to as rpb1 ${ }^{\text {sup }}$ mutations. In addition to suppressing the $\mathrm{Cs}^{-}$ phenotype of the spt5 mutants, the rpb1 ${ }^{\text {sup }}$ mutations cause two other mutant phenotypes: sensitivity to 6azauracil $\left(6 \mathrm{AU}^{\mathrm{s}}\right)$, and a weak $\mathrm{Spt}^{-}$phenotype in an SPT5 ${ }^{+}$ genetic background (Table 1).

Substantial evidence suggests that a $6 \mathrm{AU}^{\mathrm{s}}$ phenotype indicates a defect in transcription el ongation (U ptain et al. 1997). 6AU is a drug that reduces UTP and GTP levels in vivo (Exinger and Lacroute 1992), and decreased nucleotide levels have been shown to increase pausing and arrest by RN A Pol II in vitro (U ptain et al. 1997). In addition, particular mutations in RNA Pol II subunits and in the transcription el ongation factor TFIIS confer a $6 \mathrm{AU}^{\mathrm{s}}$ phenotype in yeast (Archambault et al. 1992; Exinger and Lacroute 1992; Powell and Reines 1996). Thus, the $6 \mathrm{AU} \mathrm{U}^{\mathrm{s}}$ phenotype caused by the rpb1 ${ }^{\text {sup }}$ mutations suggests that they impair transcription el ongation.

The sequence of the $\mathrm{rpb}^{\text {sup }}$ mutations was determined. Each mutant gene contains a single base pair change; rpb1-221 causes the amino acid change H1367D, and rpb1-244 causes the amino acid change E1351K. Both of these amino acid changes occur between regions $\mathrm{G}$ and $\mathrm{H}$ of Rpbl, two of the eight blocks of sequence homology conserved among the largest subunits of eukaryotic and prokaryotic DNA-directed RNA polymerases (Archambault and Friesen 1993). Interestingly, previous studies have identified other mutations in the same regi on of RPB1, and some of these mutations also cause a $6 \mathrm{AU}^{\mathrm{s}}$ and/or an $\mathrm{Spt}^{-}$phenotype (A rchambault and Friesen 1993; Berroteran et al. 1994). Two of these $6 \mathrm{AU}^{\mathrm{s}}$ rpb1 mutations, rpo21-18 and rpo21-24, cause RNA Pol II to have a decreased affinity for the transcription el ongation factor TFIIS (Wu et al. 1996). Thus, based on both their phenotypes and position, the rpb1 $1^{\text {sup }}$ mutations may cause a defect in transcription elongation.

The rpb1 $1^{\text {sup }}$ mutations might represent a particular class of rpbl mutation. If so, we would expect the suppression of spt5 $\mathrm{Cs}^{-}$mutations by rpb1 mutations to be allele specific. To test this possibility, we analyzed double mutants between the spt5 $\mathrm{Cs}^{-}$mutations and two other rpb1 mutations. The results (Table 1 ) show that suppression of spt5 mutations by rpb1 mutations is indeed allele specific. First, we tested the rpb1 mutation rpo21-18, which, as mentioned, causes a decreased affinity between RNA Pol II and TFIIS, and a 6AU ${ }^{\mathrm{s}}$ phenotype. The rpo21-18 mutation behaved in the opposite fashion from the rpb1 ${ }^{\text {sup }}$ mutations: The rpo21-18 spt5242 double mutant was extremely sick even at $30^{\circ} \mathrm{C}$ (Table 1). At $37^{\circ} \mathrm{C}$, the temperature at which the spt5242 mutant grows almost as well as wild type, the double mutant was viable. We also tested rpb1-5, which causes an amino acid change, R335C, distant from the $\mathrm{GH}$ region of $\mathrm{Rpbl}$ (Scafe et al. 1990a). This mutation also does not suppress the spt5 $\mathrm{Cs}^{-}$mutations (Table 1 ). This allele specificity indicates that Spt5 interacts directly with RNA Pol II and/or that only a particular type of defect in RNA Pol II will suppress the spt5 $\mathrm{Cs}^{-}$phenotype. Both of these possibilities are supported by re sults described in later sections.

As a second way to test whether the rpb1 $1^{\text {sup }}$ mutations cause a distinct type of transcription defect, we analyzed them in double mutants with a deletion of the gene encoding the elongation factor TFIIS. During el ongation, after each nucleotide is added to the nascent mRNA, RNA Pol II can either add another nucleotide, pause in an elongation-competent state, or arrest in an elongati on-incompetent state (Fig. 2; U ptain et al. 1997). TFIIS acts on arrested RNA Pol II, stimulating an intrinsic nuclease activity of RNA Pol II to digest a few nucleotides from the $3^{\prime}$ end of the nascent mRN A (U ptain et al. 1997). This action resets RNA Pol II into an elongationcompetent state, allowing it to make another effort to elongate through the site where it had arrested previously. In Saccharomyces cerevisiae, TFIIS is encoded by the PPR2 gene. In an otherwise wild-type background, deletion of PPR2 causes no detectable defect except to cause a $6 \mathrm{AU}^{\mathrm{S}}$ phenotype (T able 2; Exinger and Lacroute 1992; U ptain et al. 1997). The lack of a strong ppr2 phenotype is presumably because either TFIIS is partially redundant with another factor, or arrest is not a

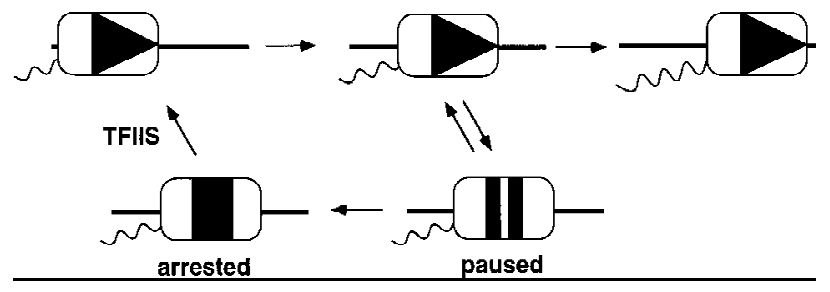

Figure 2. Model of the RNA Pol II transcription elongation cycle (for review, see U ptain et al. 1997). 
Table 2. Phenotypes of ppr2s rpbl double mutants

\begin{tabular}{lllcc}
\hline & \multicolumn{3}{c}{ Growth $\left({ }^{\circ} \mathrm{C}\right)^{\mathrm{a}}$} \\
\cline { 2 - 5 } Relevant genotype & 15 & 30 & 37 \\
\hline 1 & none & + & + & + \\
2 & ppr2s & + & + & + \\
3 & rpb1-244 ppr2s & N.D. & - & N.D. \\
4 & rpb1-221 ppr2s & - & $-1+$ & - \\
5 & spt5-242 ppr2s & - & - & $+1-$ \\
6 & spt5-276 ppr2s & - & - & $+1-$ \\
\hline
\end{tabular}

${ }^{a}$ Growth is scored as indicated in Table 1. Strains in lines 2-6 are $6 A U^{S}$. (N.D.) N ot done.

very frequent event during transcription elongation in an otherwise wild-type strain. Previous work has shown that rpo21-18 ppr2 $\Delta$ mutants are viable, consistent with the fact that rpo21-18 impairs the RN A Pol II-TFIIS interaction (Archambault et al. 1992; Wu et al. 1996). In contrast, rpb1 ${ }^{\text {sup }}$ ppr2 $\Delta$ double mutants are either extremely sick or inviable (Table 2 ). The striking difference in behavior between the rpb1 $1^{\text {sup }}$ mutations and rpo21-18 strongly supports the idea that these mutations cause two different types of defects in elongation, in turn suggesting that the rpb1 $1^{\text {sup }}$ mutations do not impair RN A Pol II-TFIIS interactions, whereas the rpo21-18 mutation does.

Possible roles for Spt5 in promoting transcription elongation

The suppression of the spt $5 \mathrm{Cs}^{-}$mutations by rpb1 mutations that are likely to cause a transcription el ongation defect suggests that Spt5 may play a role in transcription el ongation. Therefore, the spt $5 \mathrm{Cs}^{-}$mutations may cause a transcription elongation defect. Such a defect could affect el ongation in any of several different ways. We hypothesized that the role of Spt5 might be to promote transcription past potential barriers to elongation. By this model, when RNA Pol II encounters a barrier to elongation, it is much morelikely to pause or arrest in an spt5 $\mathrm{Cs}^{-}$mutant, where the essential Spt5 activity is reduced, than it would be in an $\mathrm{SPT}^{+}$strain. This leads to two predictions that can be tested genetical ly. First, if RNA Pol II arrests at a greater frequency in an spt5 $\mathrm{Cs}^{-}$ mutant, the cell's dependence on TFIIS should be greater. Second, if Spt5 activity is reduced, then reducing the rate of elongation by RNA Pol II might provide adequate time for a partial ly di sabl ed Spt5 to help RNA Pol II transcribe past the barrier, thereby suppressing the spt5 mutant defect. The next two sections present the results of these genetic tests.

Genetic interactions of Spt5 with the el ongation factor TFIIS

To test whether the requirement for TFIIS is increased in an spt5 $\mathrm{Cs}^{-}$mutant, we performed double-mutant analysis. As mentioned above, deletion of PPR2, which en- codes TFIIS, causes no detectable defect in cell growth except to cause a $6 \mathrm{AU} \mathrm{U}^{\mathrm{s}}$ phenotype. When combined with either of the spt $5 \mathrm{Cs}^{-}$mutations, however, ppr2 $\Delta$ causes a severe growth defect. Both spt5-242 ppr2 $\Delta$ and spt5-276 ppr $2 \Delta$ double mutants are inviable at both $15^{\circ} \mathrm{C}$ and $30^{\circ} \mathrm{C}$ (Fig. 3; Table 2). At $37^{\circ} \mathrm{C}$, the double mutants are viable. These results resemble those obtained previously for the spt5-242 rpo21-18 doubl e mutant (T able 1). Thus, TFIIS becomes an essential factor when Spt5 function is limiting, strongly suggesting that the spt $5 \mathrm{Cs}^{-}$mutations cause RNA Pol II to arrest more frequently.

The spt5 $\mathrm{Cs}^{-}$mutations are suppressed by a decreased rate of transcription el ongation

The second genetic test was to determine whether a decreased rate of transcription el ongation would compensate for the impaired Spt5 function in the spt5 $\mathrm{Cs}^{-}$mutants. This test was performed in two ways. First, we took advantage of a mutation in RPB2, the gene encoding the second largest subunit of RN A Pol II. This mutation, rpb2-10, causes RN A Pol II to have a decreased el ongation rate in vitro and causes a $6 \mathrm{AU}^{\mathrm{s}}$ phenotype in vivo (Powell and Reines 1996). Consistent with our model, in an spt5-242 rpb2-10 double mutant, rpb2-10 suppressed the $\mathrm{Cs}^{-}$phenotype of the spt5 mutation (Fig. 4A). As a control, we also tested another rpb2 mutation, rpb2-7, which, although it also causes a 6AU ${ }^{\mathrm{s}}$ phenotype, does not affect the RN A Pol II el ongation rate in vitro (Powell and Reines 1996). This mutation did not suppress spt5242 (Fig. 4A). Second, we treated cells with a low level of $6 \mathrm{AU}$ to decrease the concentration of nucleotides in vivo, thereby presumably decreasing the rate of transcription elongation. This test was possible because the spt5 $\mathrm{Cs}^{-}$mutations, unlike the rpb1 ${ }^{\text {sup }}$ mutations, do not cause a $6 A U^{5}$ phenotype (see Discussion). Our results show that 6AU suppresses the $\mathrm{Cs}^{-}$phenotype: The spt5 $\mathrm{Cs}^{-}$mutants grew as well as SPT5 ${ }^{+}$cells at $15^{\circ} \mathrm{C}$ on the $6 \mathrm{AU}$-containing media (Fig. 4B). Thus, slower el ongation by RN A Pol II apparently suppresses the $\mathrm{Cs}^{-}$defect of the spt5 $\mathrm{Cs}^{-}$mutants.

Genetic evidence that spt4, spt5, and spt6 mutations all affect transcription elongation

Previous work has strongly suggested that two other pro-

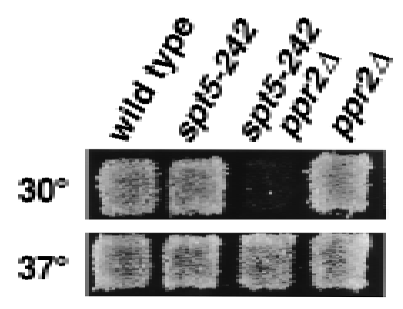

Figure 3. spt5-242 ppr2s double mutants. The indicated strains derived from a genetic cross of FY $1645 \times \mathrm{FY} 1670$. Cells were grown at $37^{\circ} \mathrm{C}$ on a YPD plate and then replica plated to YPD plates that were incubated at $30^{\circ} \mathrm{C}$ or $37^{\circ} \mathrm{C}$ for 2 days. 

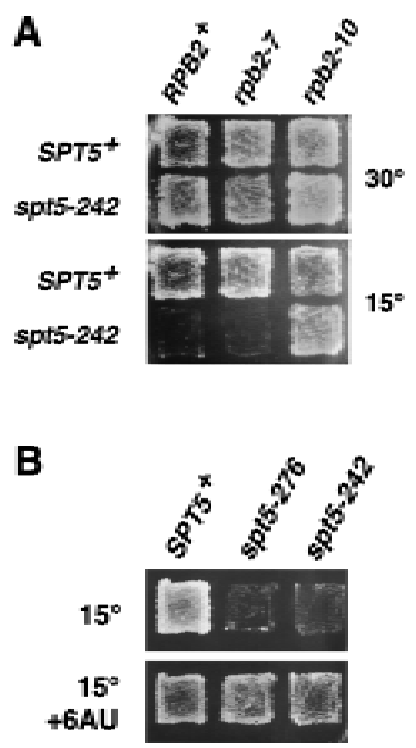

Figure 4. The cold-sensitive growth defect of the spt5 $\mathrm{Cs}^{-} \mathrm{mu}-$ tants is suppressed by decreasing the rate of transcription el ongation. (A) Suppression of spt5-242 by rpb2-10, a mutation known to decrease the rate of el ongation by RN A Pol II (Powell and Reines 1996). Growth of the indicated strains (FY1649, FY1650, FY 1651, FY1648, FY 1652, and FY1653) on SC -Ura plates at $30^{\circ} \mathrm{C}$ and $15^{\circ} \mathrm{C}$ was assayed. The photograph of the $30^{\circ} \mathrm{C}$ plate was taken after 2 days; the photograph of the $15^{\circ} \mathrm{C}$ plate was taken after 8 days. The rpb2-10 mutation also suppressed the other spt5 $\mathrm{Cs}^{-}$mutation, spt5-276 (data not shown). (B) Suppression of spt5-276 and spt5-242 by 6AU. Growth of the indicated strains (FY267, FY1647, and FY 1645) on SC -Ura plates at $15^{\circ} \mathrm{C}$ was assayed in the presence or absence of $6 \mathrm{AU}$. The plates were photographed after 8 days of incubation.

teins, Spt4 and Spt6, act with Spt5 to control transcription in vivo (Swanson and Winston 1992). Therefore, we tested whether spt4 or spt 6 mutants display defects consistent with an effect on transcription el ongation. We also included previously identified spt5 mutations that had been sel ected by their Spt ${ }^{-}$phenotype. First, we constructed and analyzed spt4 4 ppr2 $\Delta$, spt5-194 ppr2 $\Delta$, and spt6-14 ppr2 $\Delta$ double mutants. We were able to use an spt4 $\Delta$ mutation because, unlike SPT 5 and SPT6, SPT 4 is not essential for growth (Malone et al. 1993). All three double mutants show a strong temperature sensitive growth phenotype not observed for any of the single mutants (Fig. 5). These results show that the requirement for TFIIS is greatly increased in spt4, spt5, and spt6 mutants. spt4, spt5, and spt6 mutations do not generally cause synthetic lethal ity in combination with mutations in transcription factors (Winston et al . 1984), supporting the idea that the double-mutant phenotypes with ppr2s indicate an elongation defect. Second, we tested spt4 $\Delta$ and several spt 5 and spt 6 mutants for a $6 A U^{s}$ phenotype. The spt $4 \Delta$ mutation causes a strong $6 \mathrm{AU}^{\mathrm{s}}$ phenotype, as severe as that observed in a ppr $2 \Delta$ mutant (Table 3 ). For the spt5 mutants, we found that, in contrast to the spt5 $\mathrm{Cs}^{-}$mutants, both spt5-194 and spt5-4 cause 6AU ${ }^{\mathrm{s}}$ phenotypes (Table 3). Of the three spt6 mutants tested, only
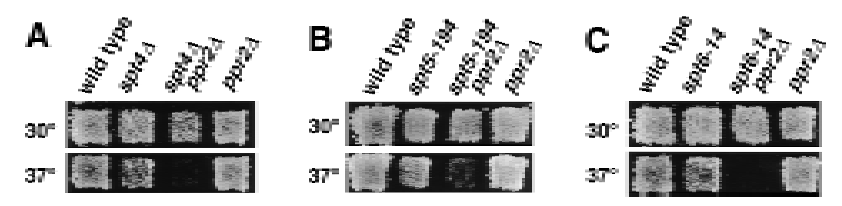

Figure 5. A ppr2s mutation causes conditional lethality in combination with spt4, spt5, and spt6 mutations. Strains of the indicated genotypes were grown as patches on YPD plates at $30^{\circ} \mathrm{C}$ and were then replica plated to duplicate YPD plates. These plates were incubated at $30^{\circ} \mathrm{C}$ or $37^{\circ} \mathrm{C}$ for 2 days and then photographed. The strains were derived from single tetrads obtained by crossing an spt strain with a ppr2 $2 \Delta$ strain as indicated.

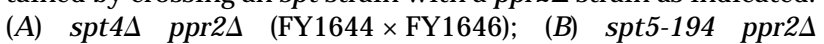

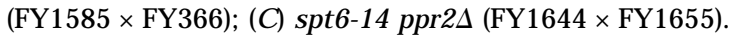

one, spt6-50, was 6AU ${ }^{\mathrm{s}}$. These mutant phenotypes strongly suggest that like Spt5, Spt4 and Spt6 play a role in transcription elongation.

\section{Identification of an Spt4-Spt5 complex}

Previously identified mutant phenotypes, including double-mutant lethality and unl inked noncomplementation, strongly suggested that Spt4, Spt5, and Spt6 might physically interact in a complex. Indeed, coimmunoprecipitation experiments detected a weak physical interaction between Spt5 and Spt6 (Swanson and Winston 1992). We have now examined the physical interactions between all three proteins, using three different methods.

First, we expressed GST-Spt4 and GST-Spt6 fusion proteins in vivo to assay their physical association with the other Spt proteins. For each fusion, we assayed its interactions with Spt5 and with Spt6. We observed that

Table 3. Growth of spt4, spt5, and spt 6 mutants on media containing $6 \mathrm{AU}$

\begin{tabular}{|c|c|c|c|c|}
\hline & \multirow{2}{*}{$\begin{array}{l}\text { Relevant } \\
\text { genotype }\end{array}$} & \multicolumn{2}{|c|}{ Growth $^{a}$} & \multirow{2}{*}{$\begin{array}{c}\text { Other } \\
\text { phenotypes }\end{array}$} \\
\hline & & $\mathrm{SC}-\mathrm{Ura}$ & $S C-U r a+6 A U$ & \\
\hline 1 & wild type & + & + & $\mathrm{Spt}^{+}$ \\
\hline 2 & ppr2s & + & - & $\mathrm{Spt}^{+}$ \\
\hline 3 & spt4 $\Delta$ & + & - & $\begin{array}{c}\text { slow growth } \\
\text { at } 37^{\circ} \mathrm{C}\end{array}$ \\
\hline 4 & spt5-242 & + & + & $\mathrm{Cs}^{-}$ \\
\hline 5 & spt5-276 & + & + & $\mathrm{Cs}^{-}$ \\
\hline 6 & spt5-4 & + & $-1+$ & \\
\hline 7 & spt5-194 & + & $-1+$ & \\
\hline 8 & spt6-14 & + & + & $\begin{array}{c}\text { slow growth } \\
\text { at } 37^{\circ} \mathrm{C}\end{array}$ \\
\hline 9 & spt6-140 & + & + & $\begin{array}{l}\text { slow growth } \\
\text { at } 37^{\circ} \mathrm{C}\end{array}$ \\
\hline 10 & spt6-50 & + & $-1+$ & \\
\hline
\end{tabular}

${ }^{\mathrm{a} A l l}$ phenotypes were scored by replica plating patches of cells to the indicated media at $30^{\circ} \mathrm{C}$. ( + ) Confluent growth after $1-2$ days; $(-1+)$ slow but definite growth after 3 days; $(-)$ little or no growth after 3 days. All spt4, spt5, and spt 6 mutations cause an Spt ${ }^{-}$phenotype. 

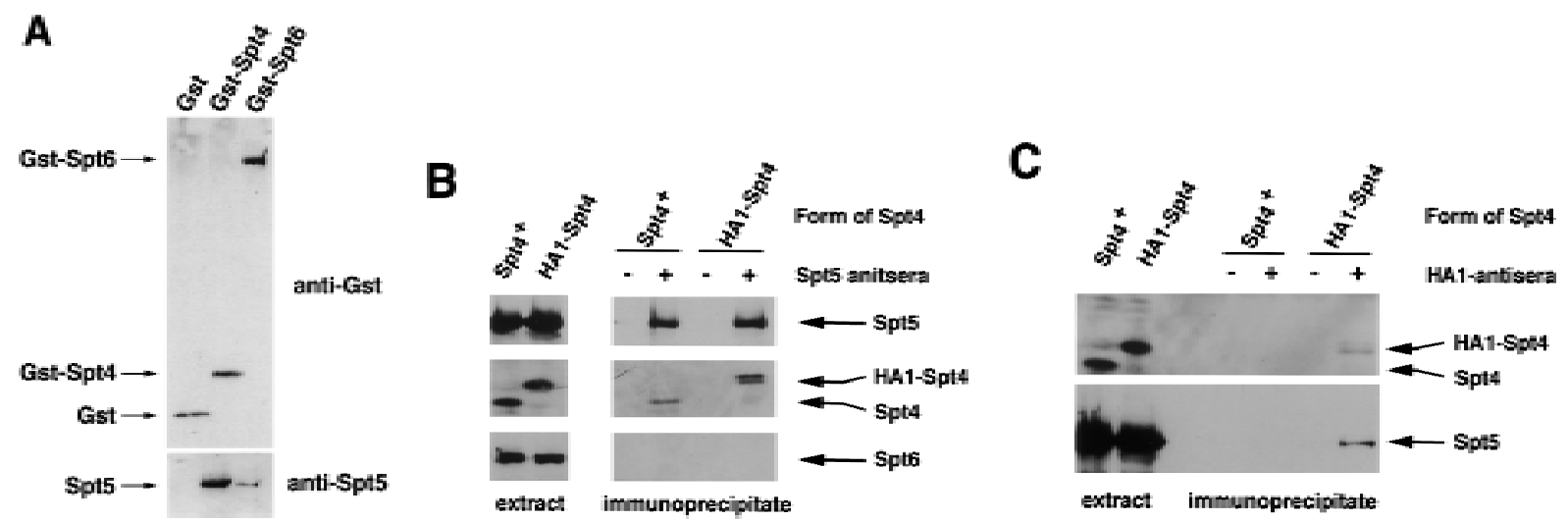

Figure 6. Identification of an Spt4-Spt5 complex. (A) Strains expressing the indicated GST fusion protein were used to prepare whole cell extracts. The GST fusion and associated proteins were isolated by affinity chromatgraphy, separated by SDS-PAGE, and immunoblotted, as described in M aterials and Methods. Shown is a blot probed with anti-GST (top) and anti-Spt5 (bottom) antibodies. (B) Spt4 coimmunoprecipitates with Spt5. Extracts were prepared from wild-type (FY 1654) and Spt4-HA 1-tagged (FY 1643) strains and used for immunopreci pitations of Spt5. Western bl ots of the immunopreci pitates were probed with anti-Spt5 (top), anti-HA 1 (middle), or anti-Spt6 (bottom) antibodies. (C) Spt5 coimmunopreci pitates with Spt4. Anti-HA 1 immunoprecipitations were carried out by use of extracts of wild-type (FY120) or HA1-Spt4-tagged (FY1643) strains. Western blots of the immunoprecipitates were probed with anti-HA1 (top) and anti-Spt5 (bottom) antibodies.

Spt5 binds strongly to GST-Spt4 and only weakly to GST -Spt6 (Fig. 6A). There was no detectable interaction of Spt5 with GST alone. A control experiment showed that the Spt5/GST-Spt4 interaction was stable even after washing the bound complexes with up to $1 \mathrm{M}$ ammonium acetate (data not shown). In contrast to Spt5, Spt6 did not detectably bind to either GST-Spt4 or GST -Spt6. These results indi cate a strong association between Spt4 and Spt5, a weak association between Spt5 and Spt6, and no detectable association between Spt4 and Spt6.

Second, we performed coimmunoprecipitation experiments to test for interactions among Spt4, Spt5, and Spt6. For these experiments, we used an HAl-epitopetagged version of Spt4. Coimmunoprecipitation of Spt4 and Spt5 was tested in both directions, and the results show that the two proteins coimmunoprecipitate (Fig. $6 \mathrm{~B}, \mathrm{C})$. In contrast, Spt6 did not detectably coimmunoprecipitate with either HA1-Spt4 (data not shown) or Spt5 (Fig. 6B).

Finally, we used a Flag-epitope-tagged version of Spt5 to partially purify Spt5 and associated proteins. When extracts made from Spt5-Flag-containing cells were applied to beads conjugated to anti-Flag antibody, both Spt5-Flag and Spt4 bound, whereas Spt6 did not (Fig. 7). Spt4 remained bound even after extensive washing in buffer containing $1 \mathrm{~m} \mathrm{KCl}$ (data not shown). As a control, extracts of wild-type cells, in which Spt5 was not epitope-tagged, were applied to anti-Flag beads. In this case, neither Spt4, Spt5, nor Spt6 bound to the beads (Fig. 7). On the basis of these three separate assays, we conclude that Spt4 and Spt5 are strongly associated in a complex and that Spt6 is at most weakly associated with this Spt4-Spt5 complex.

\section{Spt5 binds to RNA Pol II}

Two results prompted us to test whether Spt5 physically associates with RNA Pol II. First, the extensive spt5rpb1 genetic interactions suggested an Spt5-RNA Pol II interaction. Second, analysis of silver-stained SDS gels of the proteins that associate with Spt5-Flag showed the copurification, al beit substoichiometrically, of a protein of $\sim 220 \mathrm{kD}$, the size of Rpb1. Therefore, we performed Western analysis with anti-Rpb1 antibodies and found that Rpbl copurifies specifically with the Spt4-Spt5 complex (Fig. 7). Furthermore, the association of Rpb1 with the anti-Flag beads was stable to extensive washes of buffer containing $0.5 \mathrm{M} \mathrm{KCl}$ (data not shown). Thus, in addition to its genetic interactions with Rpb1 and Rpb2,

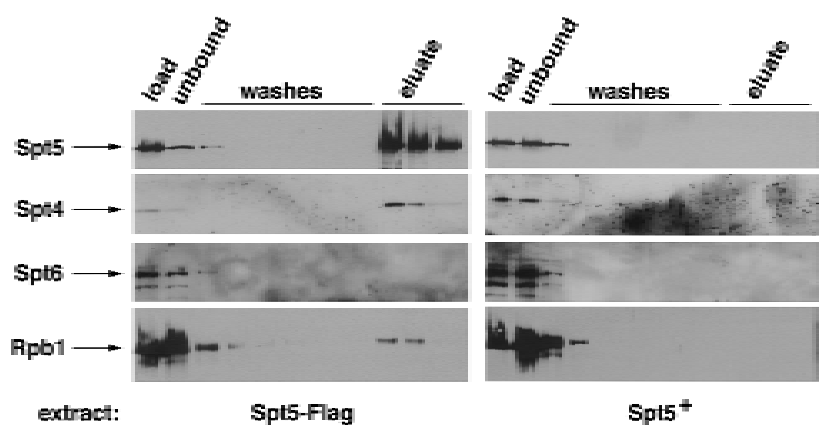

Figure 7. Purification of Spt5-Flag and associated proteins. An extract of a wild-type strain in which Spt5 was tagged with the Flag epitope was mixed with anti-Flag beads, washed, and then bound proteins were competitively el uted with a Flag peptide as described in $M$ aterials and $M$ ethods. A pproximately $1.7 \%$ of the material loaded on the anti-Flag beads, unbound material, each of the six washes, and $20 \%$ of each of the three eluted fractions were separated on an SDS-polyacrylamide gel and blotted. (Left) This blot was probed with antibodies that recognize Spt5, Spt4, Spt6, and the CTD of Rpb1. (Right) Western blots of a control experiment carried out identically and in parallel in which the extract used contained Spt5 that was not Flag tagged. 
Spt5 appears to associate with RN A Pol II in vivo. Interestingly, computer searches have reveal ed a weak homology between a conserved portion of the Spt5 family of proteins and the bacterial elongation factor N usG (Fig. 8; Wada et al. 1998), which is al so known to interact with E. coli RN A polymerase (Condon et al. 1995; Mogridge et al. 1995).

\section{Discussion}

In vivo and in vitro studies suggest an important role for Spt4, Spt5, and Spt6 in transcription elongation

Our studies have provided evidence that the transcription factors Spt4, Spt5, and Spt6 are required for transcription elongation in vivo. This conclusion is supported by four sets of results presented in this paper. First, we have shown both a genetic and a physical interaction between Spt5 and RN A Pol II. Second, we have shown that spt4, spt5, and spt6 mutations all cause phenotypes that strongly suggest el ongation defects in vivo. These phenotypes include allele-specific suppression of spt5 mutations by rpb1 and rpb2 mutations, including one rpb2 mutation that has been characterized as causing an elongation defect in vitro. In addition, spt4, spt5, and spt6 mutations all show conditional lethality in combination with ppr $2 \Delta$, a mutation that abolishes the function of the elongation factor TFIIS, and many spt4, spt5, and spt6 mutations cause a $6 \mathrm{AU} \mathrm{U}^{\mathrm{s}}$ phenotype. Third, Spt5 shows some sequence similarity to the E. coli tran-

\begin{tabular}{|c|c|c|c|}
\hline Organism & & Spt5 protein Sequence & \\
\hline 3. nerevisiae & 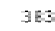 & 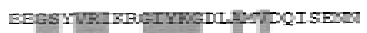 & 409 \\
\hline 3. cerevisian & $5 \pm 5$ & 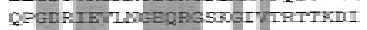 & Enti \\
\hline 3. Denerisize & SES & 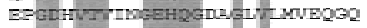 & Gil: \\
\hline 3. coneurisiate & ano & 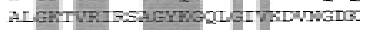 & Bat \\
\hline 3. puable & 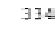 & 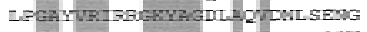 & 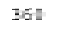 \\
\hline B. pumbe & $\triangle 13$ & 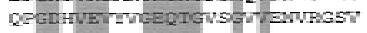 & 495 \\
\hline 3. punbe & 522 & 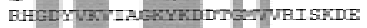 & 5 요를 \\
\hline s. pouthe & 541 & 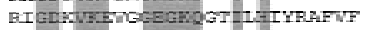 & $6 a \pi$ \\
\hline 3. puonthe & 729 & 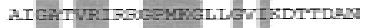 & $\pi 56$ \\
\hline c. elepars & 278 & 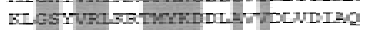 & 304 \\
\hline c. elegars & 422 & 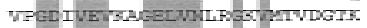 & HAE \\
\hline c. elegans & $4 T 25$ & 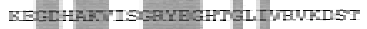 & sale \\
\hline c. elegans & 731 & 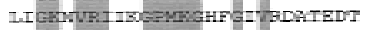 & $\operatorname{TST}$ \\
\hline C. elegans & 1255 & 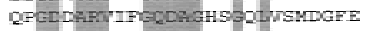 & ILEI \\
\hline if. sapiens & $=21$ & 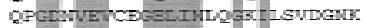 & 491 \\
\hline F. Sipiens & $4 \pi 3$ & 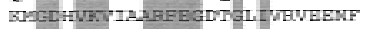 & 495 \\
\hline i. sapilens & 595 & 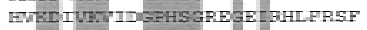 & 6.1 \\
\hline F. Sapiens & 705 & 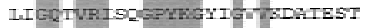 & Ta1 \\
\hline F. sepuens & $1 \pm 35$ & 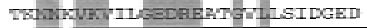 & 1062 \\
\hline Sipt5: consensus: & & & \\
\hline 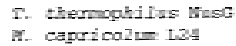 & & 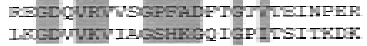 & \\
\hline
\end{tabular}

Figure 8. A repeated el ement in Spt5 is homologous to a region of N usG. Alignments of a conserved, repeated el ement in Spt5 proteins along with the consensus sequence developed by the program MEME. This consensus is similar to a motif of unknown function, KOW (Kyrpides et al. 1996), found in N usG, ribosomal protein L24, and their homologs. For comparison, the homologous sequences of the highest scoring N usG and L24 proteins are included. The accession number for $\mathrm{S}$. cerevisiae Spt5 is M 62882; for human, U56402; for Caenorhabditis elegans, Z68316; for Schizosaccharomyces pombe, Z99753; for Tetrahymena thermophila N usG, P35872; and for Mycoplasma capricolum L24, P10141. scription elongation factor NusG. Finally, we have shown that Spt4 and Spt5 form a complex; this result fits extremely well with the results in Wada et al. (1998), in which a human Spt4-Spt5 complex has been shown to affect transcription elongation in vitro and to interact with RNA Pol II.

Spt4 and Spt5 form a complex that does not contain Spt6

Although our previous genetic results were most consistent with a model in which Spt4, Spt5, and Spt6 form a complex, the biochemical data presented here show clearly that Spt4 and Spt5 form a tight complex that, at most, associates only weakly with Spt6. We observed the tight association of Spt4 and Spt5 in three different assays (Figs. 6 and 7). In contrast, both our past (Swanson and Winston 1992) and current works show that Spt5 and Spt6 interact weakly at best, and in no case was any association detected between Spt4 and Spt6. Consistent with these findings, in preliminary experiments in which we have biochemically fractionated yeast extracts, Spt4 and Spt5 cofractionate, whereas Spt6 separates away from the Spt4-Spt5 complex (data not shown). Consistent with our findings, Wada et al . (1998) purified a human Spt4-Spt5 complex that does not contain human Spt6. Thus, any model for a common function for these three proteins must account for them working in physically distinct complexes. Given the genetic evidence that Spt4, Spt5, and Spt6 work together, an Spt4-Spt5 complex may interact with Spt6 in a dynamic, but biochemically unstable fashion in vivo.

\section{Spt4, Spt5, and Spt6 are conserved regulators of transcription elongation}

Our results suggest that Spt5 serves a positive role for transcription elongation in vivo. Although we have not yet been able to obtain direct biochemical evidence that spt5 mutants are defective for elongation, Wada et al. (1998) provided a clear biochemical demonstration of a direct role for Spt4-Spt5 in transcription elongation in vitro. The sequence conservation between the yeast and human Spt4 and Spt5 proteins (Chiang et al. 1996a,b; Hartzog et al. 1996; Stachora et al . 1997) and the fact that human Spt4 functions well in yeast (Hartzog et al. 1996) suggest that these proteins are functionally conserved. Thus, it is likely that at a fundamental level, Spt4 and Spt5 carry out similar roles in yeast and humans.

Our past genetic studies of Spt4, Spt5, and Spt6 have strongly suggested that these genes also play a negative role in transcription initiation (Swanson and Winston 1992; Winston and Carlson 1992). These results fit well with the results of Wada et al. (1998), showing both negative and positive effects of human Spt4-Spt5 in vitro. Our previous conclusions about a role for Spt4, Spt5, and Spt6 in initiation were based on the ability of many spt4, spt5, and spt6 mutations to suppress loss of the Snf-Swi complex (N eigeborn et al. 1987; Swanson and Winston 1992), the deletion of a UAS element (Prelich and Win- 
ston 1993), mutations in positive activators (Denis and Malvar 1990), and the negative effects of insertion mutations in the promoter regions of genes (Swanson and Winston 1992). Although we believed these effects to occur at the level of transcription intiation, we must now consider that some of them could occur at the level of elongation. Consistent with this reinterpretation of our data, recent studies suggest a role for Snf-Swi in elongation (Brown et al. 1996) and that promoter-bound transcription factors can modify the processi vity of RN A Pol II (Bentley 1995; Krumm et al. 1995).

Spt5 and RNA Pol II interact physically and functionally to promote elongation

The allele-specific interactions we have observed between spt5 and rpb1 mutations have suggested two types of interactions between Spt5 and RN A Pol II. Allele-specific interactions between mutations in different genes are often believed to indicate a physical interaction of their protein products. The demonstration of an Rpb1Spt5 physical interaction (Fig. 7) supports this interpretation of the genetic data. The spt5 $\mathrm{Cs}^{-}$mutations, however, are also suppressed in an allele-specific manner by rpb2 mutations, as well as by treatment with 6AU. These results suggest that the spt5 $\mathrm{Cs}^{-}$mutations are suppressed by a particular type of defect in RN A Pol II that is conferred by the rpb1 ${ }^{\text {sup }}$ and rpb2-10 mutants, as well as by treatment with 6AU. Given that the rpb2-10 mutation causes RN A Pol II to have a decreased elongation rate in vitro and that $6 \mathrm{AU}$ treatment is believed to decrease the rate of transcription elongation in vivo (Powell and Reines 1996; U ptain et al. 1997), it is likely that the common defect that causes suppression of the spt5 $\mathrm{Cs}^{-}$mutations is a decrease in the processivity of RNA Pol II. Thus, the allele-specific nature of the rpb1spt5 interactions likely reflects both a functional and physical interaction between Spt5 and RNA Pol II. Additional genetic and biochemical analysis will be required to determine which RNA Pol II subunits are actually in direct contact with Spt4-Spt5.

\section{Spt4, Spt5, and Spt6 may help RNA Pol II transcribe} past nucleosome barriers

The synthetic conditional phenotypes we observed for spt ppr2 $\Delta$ double mutants suggests that, in the absence of Spt4, Spt5, and Spt6 function, RN A Pol II encounters conditions that cause it to arrest. Interestingly, a DNAbound protein can block elongation in vitro and impose a requirement for TFIIS function (Reines and M ote 1993). Previous studies have shown that nucleosomes form a barrier to el ongating RNA Pol II in vitro, suggesting that they also form a barrier in vivo (Chang and Luse 1997; U ptain et al. 1997). In addition, recent work has shown that the nucleosome remodeling activity Snf-Swi (Brown et al. 1996), and another activity, FACT (Orphanides et al. 1998), are important for elongation on chromatin templates. Spt4, Spt5, and Spt6 are distinct from these activities, as Spt5 and Spt6 are not part of either Snf-Swi (B. Cairns, pers. comm.) or FACT (D. Reinberg, pers. comm.). We propose that one role for Spt4, Spt5, and Spt6 in transcription elongation in vivo is to help RNA Pol II elongate past nucleosomes. The results in this work and those in Wada et al. (1998) have shown an interaction of Spt4-Spt5 with RN A Pol II. In addition, these investigators have shown that Spt4-Spt5 affects transcri pti on elongation in vitro on a nonchromatin template. These results suggest that Spt4-Spt5 interacts directly with RN A Pol II to control its processivity. Past biochemical analysis has shown a direct interaction of Spt6 with histones (Bortvin and Winston 1996). In addition, past genetic analyses have shown that spt4, spt5, and spt6 mutations share many phenotypes with mutations in histone genes (Hirschhorn et al. 1992; Winston and Carlson 1992; Bortvin and Winston 1996). These results suggest that Spt4, Spt5, and Spt6 may mediate interactions of RN A Pol II with chromatin. In helping RN A Pol II elongate past nucleosomes, Spt4, Spt5, and Spt6 could conceivably be required for either of two hypothetical steps: (1) nucleosome remodeling or disassembly to allow the passage of RNA Pol II, or (2) the reassembly of nucleosomes into a normal chromatin structure after the passage of RN A Pol II. Our results do not yet distinguish between these possibilities. Previous studies of Spt6 have shown that it has nucleosome assembly activity in vitro (Bortvin and Winston 1996); whether or not an Spt6 nucleosome assembly activity is relevant to the role Spt6 plays in elongation in vivo remains to be determined. Given the known biochemical interactions so far established, one possibility is that Spt4-Spt5 is primarily associated with the transcriptional apparatus, whereas Spt6 is primarily associated with nucleosomes.

The suppression of the spt5 $\mathrm{Cs}^{-}$mutations by a de creased rate of transcription elongation also supports a model in which the spt5 mutations impair the ability of RNA Pol II to elongate past nucleosomes. In this model, the rate of Spt4-Spt5 function must be appropriately coupled to the rate of RNA Pol II elongation to avoid pausing. In an spt5 $\mathrm{Cs}^{-}$mutant grown under nonpermissive conditions, Spt4-Spt5 function is reduced such that RNA Pol II has an increased probability of pausing or arresting when it encounters a nucl eosome. The pause is caused by the inability of Spt4-Spt5 to act at a normal rate to remove the nucleosome barrier. A decreased rate of el ongation by RNA Pol II, then, would allow adequate time for the weakened Spt4-Spt5 activity to remove the barrier, thereby avoiding a stalled RNA Pol II. Previous studies have suggested that $\mathrm{Cs}^{-}$mutations can impair protein-protein interactions and/or protein activity (see discussion in Noble and Guthrie 1996). Thus, the specific defect caused by the spt5 $\mathrm{Cs}^{-}$mutations could be a weakened interaction with RNA Pol II, histones, or some other transcription elongation factor. Alternatively, the spt5 $\mathrm{Cs}^{-}$mutations may interefere with an intrinsic activity of Spt5. Because the spt5 $\mathrm{Cs}^{-}$mutations do not cause a $6 \mathrm{AU}^{\mathrm{s}}$ phenotype and are actually suppressed by $6 \mathrm{AU}$, the el ongation defect that they cause is very likely to be distinct from that caused by rpbl, 
rpb2, or other spt mutations that cause a $6 \mathrm{AU}^{\mathrm{s}}$ phenotype and are believed to impair elongation.

In conclusion, our work has provided strong genetic evidence for a role in transcription el ongation for yeast Spt4, Spt5, and Spt6. Biochemical experiments on the human Spt4 and Spt5 proteins also strongly suggest a role in el ongation (Wada et al . 1998). Future experiments will be aimed to discover other proteins that physically associate with both the Spt4-Spt5 complex and with Spt6, to address how these factors might play both positive and negative roles in transcription elongation in vivo, and to develop in vitro assays for these factors on chromatin templates. It will be interesting to determine whether Spt4, Spt5, and Spt6 are required for the function of transcriptional activators that work by overcoming a transcriptional pause, such as Drosophila hsp70 (Lis and Wu 1993) or HIV Tat (Jones 1997).

\section{Materials and methods}

Media and genetic methods

The S. cerevisiae strains used in this study (T able 4) are isogenic to S288C and are GAL2+ (Winston et al. 1995). Strain constructions and other genetic manipulations were carried out by standard methods. Yeast media, including rich media (YPD), minimal media (SD), and synthetic complete media lacking uracil (SC -U ra) were made as described previously (Rose et al. 1990). Strains containing the rpb1 $\Delta 187:$ HIS3 and rpb2 $2297:$ HIS3 deletions were made as described previously ( $\mathrm{N}$ onet et al. 1987; Scafe et al. 1990b). 6AU sensitivity was scored on SC -Ura plates with $50 \mu \mathrm{g} / \mathrm{ml}$ of $6 \mathrm{AU}$. The ppr $2 \Delta:$ :hisG deletion was integrated by use plasmid pJD3. Strains carrying the plasmidborne rpb1 and rpb2 mutations were created by plasmid shuffle methods (Guthrie and Fink 1991) by use of host strains with either rpb1 $\Delta 187:$ HIS3 or rpb2 $\Delta 297:$ HIS3. Preliminary experiments utilized a derivative of SPT5 that had been tagged with the Myc epitope. Although this epitope was not used, several of the strains listed do carry Spt5-M yc. All epitope-tagged alleles of SPT4, SPT5, and SPT6 used in this work were phenotypically indistinguishable from the wild-type genes. Double-mutant strains that are inviable at $30^{\circ} \mathrm{C}$ were isolated by germination of dissected tetrads at $37^{\circ} \mathrm{C}$.

\section{Plasmids}

pRP187 and pRP112 are described in Nonet et al. (1987). pRP212, pRP297, pRP2-7(U), and pRP2-10(U) are described in Scafe et al. (1990b). pRPB1-5 is described in Scafe et al . (1990a). pJA509 and pJA483 are described in Archambault et al. (1992). pFW45 (Winston et al. 1984), pYST 138 (Som et al. 1988), and pHB59 (a gift of Henry Baker, University of Florida, Gainesville) were used to make the HIS4, TU B2, and TPI 1 probes for N orthern blots. pGH25 is a derivative of pMALcRI (New England Biolabs) fused in-frame to the 3' EcoRI site of SPT5. This results in expression of a fusion of MBP to amino acids 807-1063 of Spt5. pGH123 contains full-length SPT4 fused in frame to M BP in PM ALCRI. The HA 1 epitope-tagged al lele of SPT 4 was created by subcloning the HindlII fragment of pBM 56 (Malone et al. 1993), containing HA 1-SPT4, into pRS306 (Sikorski and Hieter 1989) to create pGH 90. The SPT5-Flag al lel e was constructed by site-directed mutagenisis of pGH17, a derivative of pBluescriptIIKS+ containing the Kpnl-Xhol fragment of SPT5, by use of oligonucleotide OGH52, 5'-CTCCTTTTGGTGATTACTTGT-
CATCGTCGTCCTTGTAGTCATGACCTCCCCATGTAC-3'. The mutagenized Kpnl-Xhol SPT5-Flag fragment was cloned into pRS306, creating plasmid pGH184. pMS4 is described in Swanson et al. (1991), and pBM 24 contains the SPT5 genomic DNA fragment from pMS4 in pBM 453, a TRP1 CEN shuttle vector. pG H84 contains full-length SPT4 fused in-frame to GST in pEM BL-GST (Kranz et al. 1994). pGH 85 contains full-length SPT6 fused in-frame to GST in pEMBL-GST. GST was expressed from plasmid pYBS305 (pEMBL-GST derivative generously provided by E. Elion, Harvard Medical School, Boston, MA). pGH189 is a derivative of pRP112 that lacks the AatIIBstEII fragment upstream of RPB1. pGH188 is a derivative of pRP112 that lacks an internal EcoRI-Xbal fragment of RPB1.

\section{I solation of spt5 $\mathrm{Cs}^{-}$mutants}

The spt5 $\mathrm{Cs}^{-}$mutations were isolated by mutagenizing plasmid pBM 24 with hydroxylamine as described (Rose et al. 1990). The mutagenized plasmid was used to transform strain FY849 and the $\mathrm{Trp}^{+}$transformants were replica plated to 5FOA plates to select for loss of the wild-type SPT5 plasmid pM S4. 5FOA-resistant colonies were then replica plated to YPD plates that were incubated at $15^{\circ} \mathrm{C}$ and $30^{\circ} \mathrm{C}$ to identify colonies defective for growth at $15^{\circ} \mathrm{C}$. Each candidate was retested by isolating the mutant plasmid and using it to retransform strain FY849 to determine if the $\mathrm{Cs}^{-}$phenotype was plasmid linked. Two spt5 mutations conferring a $\mathrm{Cs}^{-}$growth defect were identified and recombined into the S. cerevisiae genome, replacing SPT5 ${ }^{+}$. When integrated, these spt5 mutations, spt5-242 and spt5-276, still cause a $\mathrm{Cs}^{-}$phenotype and al so confer a weak Spt $^{-}$phenotype. Linkage analysis and plasmid complementation were used to verify that these mutant phenotypes were caused by the spt5 mutations.

Isolation of suppressors of the spt5 $\mathrm{Cs}^{-}$mutations and identification of these suppressors as rpbl mutations

To isolate extragenic suppressors of the spt $5 \mathrm{Cs}^{-}$mutations, the spt5-242 strain FY1635 and the spt5-276 strain FY1634 were mutagenized with 300 ergs $/ \mathrm{mm}^{2}$ of UV light, allowed to grow into colonies, and then replica plated to YPD and incubated at $15^{\circ} \mathrm{C}$. Colonies that grew at $15^{\circ} \mathrm{C}$ were purified and retested for $\mathrm{a} \mathrm{Cs}^{+}$phenotype. The detailed analysis of most of these suppressors will be described elsewhere. Two of the suppressor mutations were shown to be mutations in RPB1 by several steps. These mutations suppressed the $\mathrm{Cs}^{-}$phenotype of the spt $5 \mathrm{mu}-$ tatons and also caused a mild $\mathrm{Spt}^{-}$phenotype in an $\mathrm{SPT}^{+}$genetic background. To clone the gene corresponding to this complementation group, strain FY 1637 was transformed with a plasmid li brary of yeast genomic DN A (Rose et al. 1987) Transformants were screened for an $\mathrm{Spt}^{+}$phenotype ( $\mathrm{His}^{-}$and Lys). Candidate plasmids were isolated and used to retransform strains FY1637 and FY1636 to determine whether all of the mutant phenotypes could be complemented by the plasmid. The one plasmid that passed these tests was shown to contain RPB1 by DNA sequence analysis. Experiments with plasmid pGH189, which contains only RPB1, confirmed that RPB1 was sufficient to complement all the mutant phenotypes of the spt5 $\mathrm{Cs}^{-}$suppressors. In addition, $\mathrm{pGH} 188$, which lacks the internal EcoRI-Xbal fragment of RPB1, could not complement the suppressors. Finally, both suppressors were shown to be allelic to RPB1 by linkage analysis.

\section{Sequence analysis of $\mathrm{rpb}^{\text {sup }}$ mutations}

The two rpb1 $1^{\text {sup }}$ mutations were cloned from strains FY 1637 and FY 1638 into plasmid pRP112, by use of the method of gap 
Hartzog et al.

Table 4. S. cerevisiae strains

\begin{tabular}{|c|c|}
\hline Strain & Genotype \\
\hline FY2 & MAT $\alpha$ ura3-52 \\
\hline FY 120 & MATa his4-912 Iys2-128 trp1 $\Delta 63$ ura3-52 leu2 $\Delta 1$ \\
\hline FY 267 & MAT $\alpha$ his4-912 $\delta$ lys2- $128 \delta$ leu $2 \Delta 1$ \\
\hline FY 366 & 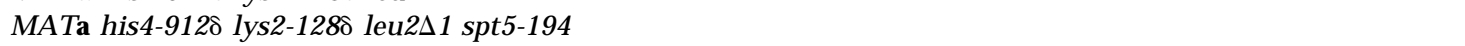 \\
\hline FY849 & 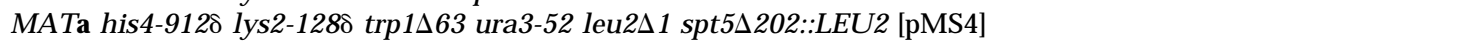 \\
\hline FY 1585 & 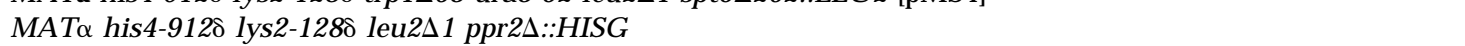 \\
\hline FY 1634 & 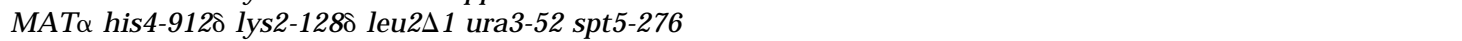 \\
\hline FY 1635 & 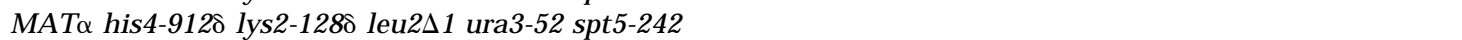 \\
\hline FY 1636 & 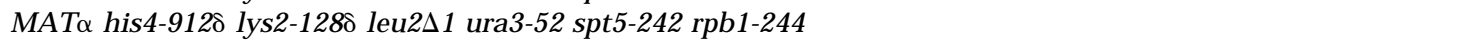 \\
\hline FY 1637 & 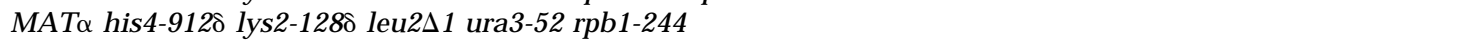 \\
\hline FY 1638 & 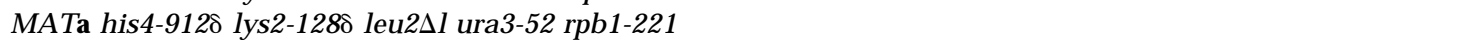 \\
\hline FY 1639 & 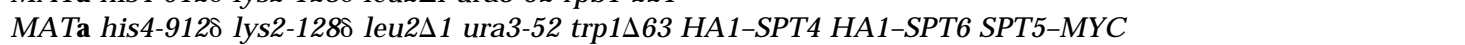 \\
\hline FY 1640 & 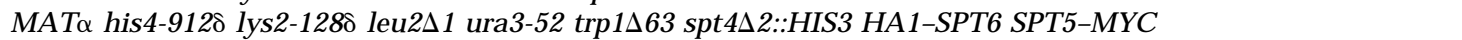 \\
\hline FY 1641 & $\begin{array}{l}\text { MAT } \alpha \text { his4-912 lys2-128 leu2 } 21 \text { ura3-52 spt6 } 4:: \text { LEU } 2 \text { SPT5-MYC ade8 [pGH85 =pGAL-GST-SPT6 } 2 \mu \text { URA3 } \\
\text { leu2d] }\end{array}$ \\
\hline FY 1642 & 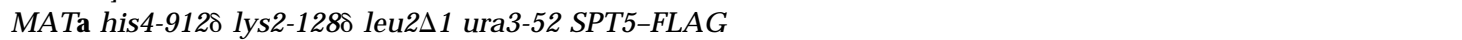 \\
\hline FY 1643 & 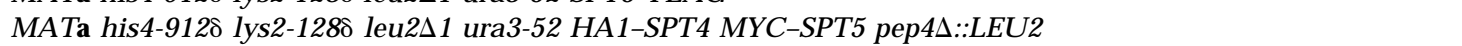 \\
\hline FY 1644 & 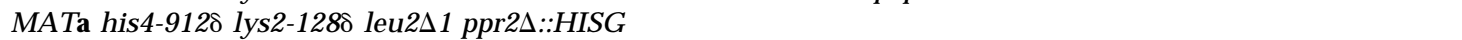 \\
\hline FY 1645 & 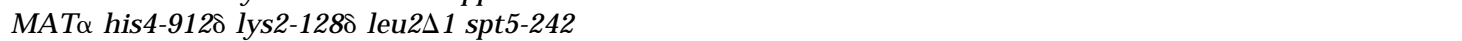 \\
\hline FY 1646 & MAT $\alpha$ his4-912 lys2-128 leu2 11 spt4 $2::$ HIS3 \\
\hline FY 1647 & 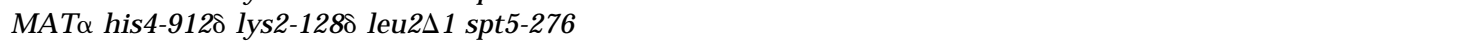 \\
\hline FY 1648 & 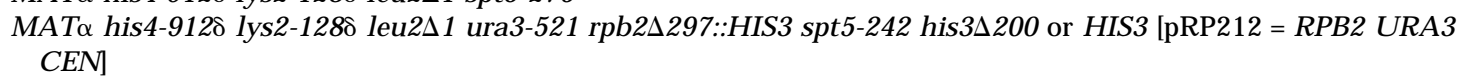 \\
\hline FY 1649 & 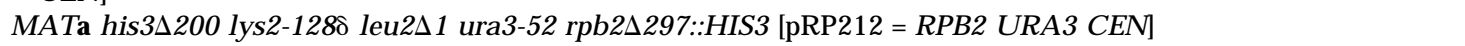 \\
\hline FY 1650 & 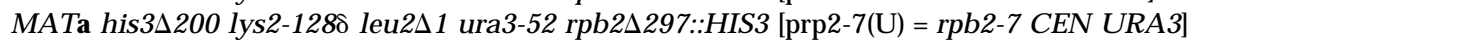 \\
\hline FY 1651 & MATa his3 200 lys2-128 leu2 1 ura3-52 rpb2 $297::$ HIS3 [pRP2-10(U) =rpb2-10 U RA3 CEN ] \\
\hline FY 1652 & 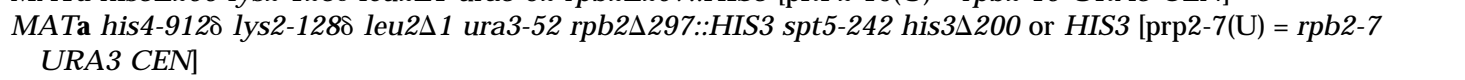 \\
\hline FY 1653 & 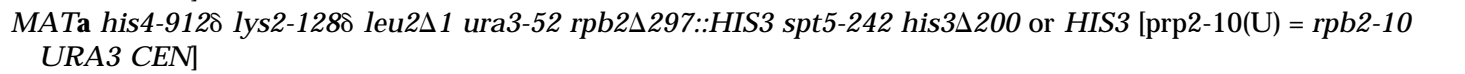 \\
\hline FY 1654 & 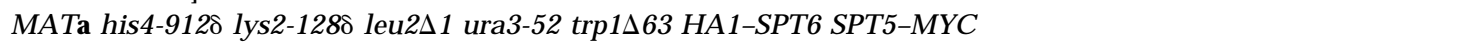 \\
\hline FY 1655 & 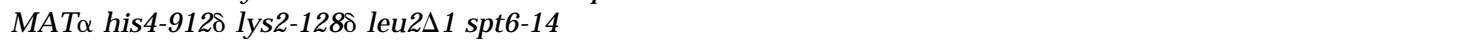 \\
\hline FY 1659 & $\begin{array}{l}\text { MATa lys2-128 leu2 } 21 \text { ura3-52 trp1 } \Delta 63 \text { spt5-242 rpb1 } \Delta 187:: H I S 3 \text { his3 } 200 \text { or HIS3 [p]A509 =rpo21-18 CEN } \\
\text { TRP1] }\end{array}$ \\
\hline FY 1660 & 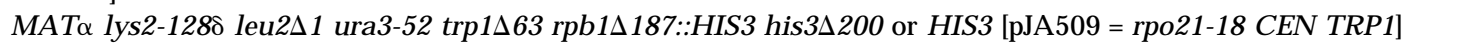 \\
\hline FY 1663 & 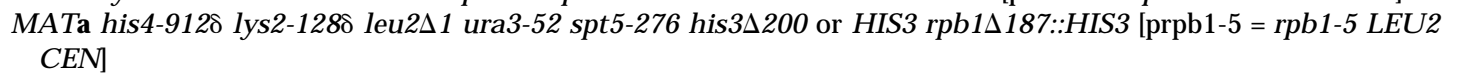 \\
\hline FY 1665 & 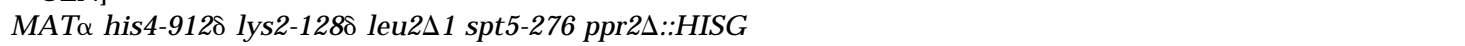 \\
\hline FY 1666 & 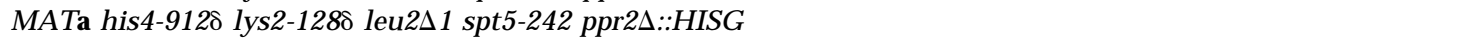 \\
\hline FY 1667 & 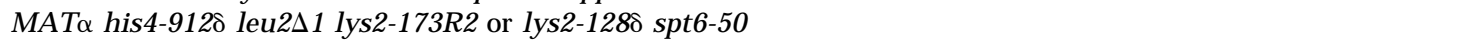 \\
\hline FY 1668 & MATahis4-9128 lys2-128 spt5-4 \\
\hline FY 1669 & 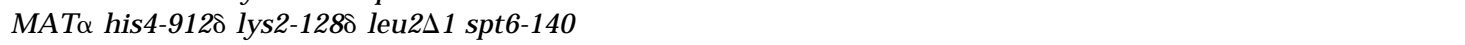 \\
\hline FY 1670 & 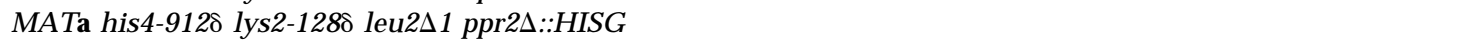 \\
\hline FY 1671 & 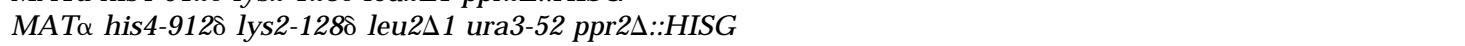 \\
\hline FY 1672 & MAT $\alpha$ lys2-128 leu2 21 ura3-52 spt5-242 \\
\hline FY 1673 & MATa lys2-128 leu2 1 ura3-52 spt5-276 his3 200 \\
\hline FY 1686 & 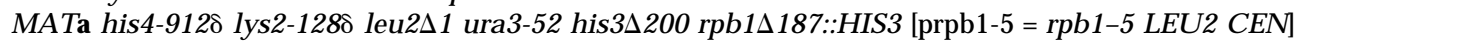 \\
\hline FY 1687 & 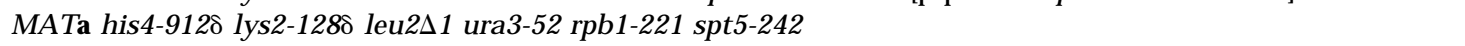 \\
\hline FY 1688 & 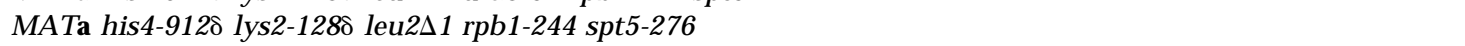 \\
\hline FY 1689 & 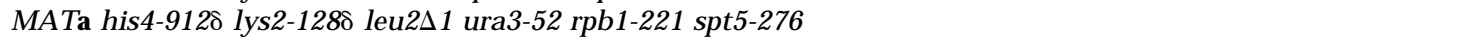 \\
\hline
\end{tabular}

repair (Guthrie and Fink 1991). Based on the gap-repair results, the 2.7-kb Xbal-SnaBI fragment of RPB1 was sequenced for each mutant at the Biopolymer Facility in the Department of Genetics, Harvard M edical School. In each case, a single basesubstitution mutation was identified. To verify that this mutation caused the suppressor phenotype, the Xbal-SnaBI fragment of each mutant was subcloned into an otherwise wild-type RPB1 gene in pRP112. For both rpb1-244 and rpb1-221, these reconstructed plasmids, pGH202 and pGH203, were phenotypically indistinguishable from the original mutant isolates.

Northern analysis

For Northern analysis, cells were grown in SD media supplemented with necessary amino acids to a density of $0.5 \times 10^{7}$ to $2.0 \times 10^{7}$ cells $/ \mathrm{ml}$. RN A was isolated from cells by a hot phenol 
method (Ausubel et al. 1988), quantitated with a spectrophotometer, and $10 \mu \mathrm{g}$ of each sample was separated on an agaroseformal dehyde gel, blotted to Genescreen, and probed as described in Swanson et al. (1991). ${ }^{32} \mathrm{P}$-Labeled probes were made by nick translation with a kit purchased from Boehringer $M$ annheim Biochemicals.

\section{Analysis of protein-protein interactions}

Strains were grown to a density of $1 \times 10^{7}$ to $4 \times 10^{7}$ cells $/ \mathrm{ml}$, and extracts were prepared by the bead-beating method (Eisenmann et al. 1992). Cells were lysed in buffer containing $25 \mathrm{~mm}$ $\mathrm{NaPO}_{4}, 0.1 \mathrm{M} \mathrm{KOAC}, 2 \mathrm{~mm} \mathrm{MgAc}$, and 10\% glycerol. Unless otherwise noted, all manipulations of protein were carried out at $4^{\circ} \mathrm{C}$ and in the presence of the following protease inhibitors: aprotinin $(1.72 \mu \mathrm{g} / \mathrm{ml})$; pepstatin A $(1 \mu \mathrm{g} / \mathrm{ml})$; chymotatin $(0.1$ $\mu \mathrm{g} / \mathrm{ml})$; E64 $(7.2 \mu \mathrm{g} / \mathrm{ml})$; phosporamidon $(1.1 \mu \mathrm{g} / \mathrm{ml})$; and PM SF (1 $\mathrm{mm}$ ).

For the GST-binding experiments, strain FY 1639 was transformed with pYBS305 (GST) and strain FY 1640 was transformed with pGH84 (GST-Spt4). All GST fusion proteins were functional in vivo. The FY 1639 and FY 1640 transformants, as well as strain FY1641 (expressing GST-Spt6 from pGH85), were grown in SC $-U$ ra with $2 \%$ raffinose as the carbon source to $1 \times 10^{7}$ to $4 \times 10^{7}$ cells $/ \mathrm{ml}$. Galactose was then added to $2 \%$, and cells were grown for $3 \mathrm{hr}$ at $30^{\circ} \mathrm{C}$ and then processed for extracts as described above. GST pull-down experiments were performed by mixing $500 \mu \mathrm{g}$ of protein extracts with $200 \mu \mathrm{l}$ of glutathione-Sepharose (Pharmacia) in a volume of $500 \mu \mathrm{l}$ in the presence of $0.5 \%$ Triton X-100. After gentle mixing for $1 \mathrm{hr}$ at $4^{\circ} \mathrm{C}$, the beads were pelleted, the supernatant was removed, and the beads were washed in five vol umes of Iysis buffer adjusted to $0.5 \%$ Triton and $0.4 \mathrm{~m}$ ammonium acetate. After washing, $40 \mu \mathrm{l}$ of beads was removed and mixed with SDS-loading buffer for polyacrylamide gel el ectrophoresis.

Spt5-Flag was purified by mixing $\sim 6 \mathrm{mg}$ of an extract from strain FY 1642 with $\sim 50 \mu$ of M 2 anti-Flag beads (Kodak) and mixing gently for $6 \mathrm{hr}$. The beads were pelleted, the unbound material was removed, and the beads were washed six times in wash buffer ( $25 \mathrm{~mm}$ HEPES at $\mathrm{pH} 7.4,1 \mathrm{~mm}$ EDTA, $0.02 \%$ $\mathrm{NP}-40,3 \mathrm{mM} \mathrm{M} \mathrm{gCl}, 10 \%$ glycerol, $1 \mathrm{~mm}$ DTT, $0.2 \mathrm{M} \mathrm{KCl}$ ) with 5 min of gentle mixing between washes. The bound proteins were eluted by adding $50 \mu \mathrm{l}$ of wash buffer containing $2 \mathrm{mg} / \mathrm{ml}$ of the Flag peptide, Asp-Tyr-Lys-Asp-Asp-Asp-Asp-Lys (Research Genetics), and incubating for $30 \mathrm{~min}$ before pelleting the beads gently and removing the eluate. This elution step was repeated two to three times. A control experiment was carried out in parallel in which anti-Flag beads were mixed with an extract of FY 267 cells, in which Spt5 lacks the Flag epitope, to determine the level of nonspecific binding of proteins to the beads.

Immunoprecipitations were performed by mixing $250 \mu \mathrm{g}$ of protein extract (prespun for $10 \mathrm{~min}$ at $4^{\circ} \mathrm{C}$ in a microcentrifuge to remove protein aggregates) in lysis buffer plus $0.5 \mathrm{M}$ ammonium acetate and $0.1 \%$ T ween 20 with $\sim 50 \mu$ of anti-mouse (for anti-HA1 immunoprecipitations) or anti-rabbit (for anti-Spt5 immunoprecipitations) IgG (Sigma Immunochemicals) in a final volume of $250 \mu \mathrm{l}$. After $30 \mathrm{~min}$ of incubation with gentle mixing, the beads were removed by low-speed centrifugation and the supernatant was transferred to a clean tube and mixed with $3 \mu \mathrm{l}$ of affinity purified anti-Spt5 or $5 \mu \mathrm{l}$ of anti-HA 1 antibody as appropriate. After $1 \mathrm{hr}$ of gentle mixing in the presence of the primary antibody, the reactions were centrifuged for $10 \mathrm{~min}$ in a microcentrifuge and transferred to a clean tube with $50 \mu \mathrm{l}$ of the appropriate anti-IgG beads for an additional $1 \mathrm{hr}$ of incubation. Finally, the beads were washed five times by centrifuga- tion, removal of the supernatant and addition of $0.5 \mathrm{ml}$ of lysis buffer plus $0.5 \mathrm{~m}$ ammonium acetate and $0.1 \%$ Tween- 20 followed by $5 \mathrm{~min}$ of gentle rocking. After the final wash, the beads were resuspended in SDS-sample loading buffer for gel el ectrophoresis.

\section{Antibodies and immunoblots}

The anti-Spt4 and -Spt5 antibodies were directed against maltose-binding protein (M BP) fusion proteins produced from plasmids pGH123 and pGH25, respectively, with the MBP protein fusion and purification system from $\mathrm{N}$ ew England Biolabs (Beverly, MA), according to their instructions. Rabbits were immunized with the MBP-Spt4 and M BP-Spt5 fusion proteins by Cocalico Biologicals (Reamstown, PA). The Spt5 antibody was affinity purified by coupling MBP al one and MBP-Spt5 to Affigel (Bio-Rad), preclearing the crude antisera agai nst the MBP-affigel, and then purifying the Spt5 specific antibodies on the MBPSpt5-affigel as described previously (Harlow and Lane 1988). The anti-HA 1 antibody was produced by BabCo (Berkeley, CA). The anti-Rpbl antibody is a mouse monoclonal antibody, 8 WG 16, directed against the carboxy-terminal domain (CTD) of RN A Pol II (Thompson et al. 1989). All immunoblots were performed by separating the proteins of interest on $7.5 \%-16 \%$ or $7.5 \%-20 \%$ gradient SDS-polyacrylamide gels and transferring them to Immobilon-N C membranes (Millipore). Western blots were probed under standard conditions (Harlow and Lane 1988). HRP-coupled secondary antibodies were obtai ned from Bio-Rad. Blots were developed with the Amersham ECL kit according to their instructions.

\section{Computer searches}

Homology searches, by use of BLAST (Altschul et al. 1990), identified a repeated, conserved sequence element among Spt5 proteins. With the program MEME (Bailey and Elkan 1994), a consensus for this sequence element was developed. The consensus sequence was then used to search a nonredundant protein database by use of MAST (Bailey and Elkan 1994). For each potential match to the motif, MAST calculates the probability that a random sequence would match the motif as well as the potential match. MAST then calculates the number of expected occurrences of a match to the motif at that probability level as if it were searching a random database of the same size as the nonredundant database; this is termed the $\mathrm{E}$ value. Of the 52 proteins with matches to the motif with an $E$ value of less than 1, 41 occurred in Spt5 proteins, ribosomal protein L24 proteins or in N usG proteins.

\section{Acknowledgments}

We thank Rick Young, Jim Friesen, Judy Davie, Caroline Kane, and Elaine Elion for plasmids; Frank McKeon and Clyde Denis for antibodies; Judy Davie and Caroline Kane for advice on 6AU plates; Steve Buratowski, Brad Cairns, and Toshio Tsukiyama for hel pful conversations; and Brad Cairns and Ting Wu for critical reading of the manuscript. During this work, G.H. was a Charles A. King Trust Research Fellow supported by the Fleet Bank of Massachusetts. This work was supported by $\mathrm{N}$ ational Institutes of Health grant GM 32967 to F.W.

The publication costs of this article were defrayed in part by payment of page charges. This article must therefore be hereby marked "advertisement" in accordance with 18 USC section 1734 solely to indicate this fact. 


\section{References}

Altschul, S.F., W. Gish, W. Miller, E.W. Myers, and D.J. Lipman. 1990. Basic local alignment search tool. J. Mol. Biol. 215: 403-410.

Archambault, J. and J.D. Friesen. 1993. Genetics of eukaryotic RN A polymerase I, II, and III. Micro. Rev. 57: 703-724.

Archambault, J., F. Lacroute, A. Ruet, and J.D. Friesen. 1992. Genetic interaction between transcription el ongation factor TFIIS and RNA polymerase II. Mol. Cell. Biol. 12: 4142-4152.

Ausubel, F.M., R. Brent, R.E. Kingston, D.D. Moore, J.G. Seidman, J.A. Smith, and K. Struhl. 1988. Current protocols in molecular biology. Greene Publishing Associates/WileyInterscience, N ew York, NY.

Bailey, T.L. and C. Elkan. 1994. Fitting a mixture model by expectation maximization to discover motifs in biopolymers. In Proceedings of the second international conference on intelligent systems for molecular biology, pp. 28-36. AAAI Press, Menlo Park, CA.

Basrai, M.A., J. Kingsbury, D. Koshland, F. Spencer, and P. Hieter. 1996. Faithful chromosome transmission requires Spt4p, a putative regulator of chromatin structure in Saccharomyces cerevisiae. Mol. Cell. Biol. 16: 2838-2847.

Bentley, D.L. 1995. Regulation of transcriptional el ongation by RN A polymerase II. Curr. O pin. Genet. Dev. 5: 210-216.

Berroteran, R.W., D.E. Ware, and M. Hampsey. 1994. The sua8 suppressors of Saccharomyces cerevisiae encode replace ments of conserved residues within the largest subunit of RN A polymerase II and affect transcription start site selection similarly to sua7 (TFIIB) mutations. Mol. Cell. Biol. 14: 226-237.

Bortvin, A. and F. Winston. 1996. Evidence that Spt6 controls chromatin structure by a direct interaction with histones. Science 272: 1473-1476.

Brown, S.A., A.N . Imbalzano, and R.E. Kingston. 1996. Activator-dependent regulation of transcriptional pausing on nucleosomal templates. Genes \& Dev. 10: 1479-1490.

Chang, C.-H. and D.S. Luse. 1997. The H3/H4 tetramer blocks transcript el ongation by RN A polymerase II in vitro. J. Biol. Chem. 272: 23427-23434.

Chiang, P., E. Fogel, C. Jackson, K. Lieuallen, G. Lennon, X. Qu, S. Wang, and D. Kurnit. 1996a. Isolation, sequencing, and mapping of the human homologue of the yeast transcription factor, SPT5. Genomics 38: 421-424.

Chiang, P., S. Wang, P. Smithivas, W. Song, E. Crombez, A. Akhtar, R. Im, J. Greenfield, S. Ramamoorthy, M. Van Keuren et al. 1996b. Isolation and characterization of the human and mouse homologues (SU PT4H and Supt4h) of the yeast SPT4 gene. Genomics 34: 368-375.

Condon, C., C. Squires, and C.L. Squires. 1995. Control of rRNA transcription in Escherichia coli. Microbiol. Rev. 59: 623-645.

Denis, C.L. and T. M alvar. 1990. The CCR4 gene from Saccharomyces cerevisiae is required for both nonfermentative and spt-mediated gene expression. Genetics 124: 283-291.

Ding, H.F., S. Rimsky, S.C. Batson, M. Bustin, and U. Hansen. 1994. Stimulation of RN A polymerase Il el ongation by chromosomal protein HMG-14. Science 265: 796-799.

Eisenmann, D.M., K.M. Arndt, S.L. Ricupero, J.W. Rooney, and F. Winston. 1992. SPT 3 interacts with TFIID to allow normal transcription in Saccharomyces cerevisiae. Genes \& Dev. 6: 1319-1331.

Exinger, F. and F. Lacroute. 1992. 6-Azauracil inhibition of GTP biosynthesis in Saccharomyces cerevisiae. Curr. Genet. 22: 9-11.
Guthrie, C. and G.R. Fink. 1991. Guide to yeast genetics and molecular biology. In Methods in Enzymology (ed. J.N . A belson and M.I. Simon), Vol. 194. Academic Press, San Diego, CA.

Harlow, E. and D. Lane. 1988. Antibodies: A laboratory manual. Cold Spring Harbor Laboratory, Cold Spring Harbor, NY.

Hartzog, G.A., M.A. Basrai, S.L. Ricupero-Hovasse, P. Hieter, and F. Winston. 1996. Identification and analysis of a functional human homolog of the SPT4 gene of Saccharomyces cerevisiae. Mol. Cell. Biol. 16: 2848-2856.

Hirschhorn, J.N ., S.A. Brown, C.D. Clark, and F. Winston. 1992. Evidence that SNF2/SWI2 and SN F5 activate transcription in yeast by altering chromatin structure. Genes \& Dev. 6: 2288-2298.

Jones, K.A. 1997. Taking a new TAK on TAT transactivation. Genes \& Dev. 11: 2593-2599.

Kranz, J.E., B. Satterberg, and E.A. Elion. 1994. The M AP kinase Fus3 associates with and phosphorylates the upstream signaling component Ste5. Genes \& Dev. 8: 313-327.

Krumm, A., L.B. Hickey, and M. Groudine. 1995. Promoterproximal pausing of RNA polymerase II defines a general rate-limiting step after transcription initiation. Genes \& Dev. 9: 559-572.

Kyrpides, N.C., C.R. Woese, and C.A. Ouzounis. 1996. KOW: A novel motif linking a bacterial transcription factor with ribosomal proteins. Trends Biochem. Sci. 21: 425-426.

Lis, J. and C. Wu. 1993. Protein traffic on the heat shock promoter: Parking, stalling, and trucking al ong. Cell 74: 1-4.

Malagon, F. and A. Aguilera. 1996. Differential intrachromosomal hyper-recombination phenotype of spt4 and spt6 mutants of S. cerevisiae. Curr. Genet. 30: 101-106.

Malone, E.A., J.S. Fassler, and F. Winston. 1993. Molecular and genetic characterization of SPT4, a gene important for transcription initiation in Saccharomyces cerevisiae. Mol. Gen. Genet. 237: 449-459.

M ogridge, J., T.-F. M ah, and J. Greenblatt. 1995. A protein-RN A interaction network facilitates the template-independent cooperative assembly on RN A polymerase of a stable antitermination complex containing the $\lambda \mathrm{N}$ protein. Genes $\&$ Dev. 9: 2831-2844.

N eigeborn, L., J.L. Celenza, and M. Carlson. 1987. SSN20 is an essential gene with mutant alleles that suppress defects in SU C2 transcription in Saccharomyces cerevisiae. Mol. Cell. Biol. 7: 672-678.

N oble, S.M. and C. Guthrie. 1996. Identification of novel genes required for yeast pre-mRNA splicing by means of cold-sensitive mutations. Genetics 143: 67-80.

Nonet, M., D. Sweester, and R.A. Young. 1987. Functional redundancy and structural polymorphism in the large subunit of RNA polymerase II. Cell 50: 909-915.

Orphanides, G., G. LeRoy, C.-H. Chang, D.S. Luse, and D. Reinberg. 1998. FACT, a factor that facilitates transcript elongation through nucleosomes. Cell (in press).

Powell, W. and D. Reines. 1996. Mutations in the second largest subunit of RN A polymerase II cause 6-Azauracil sensitivity in yeast and increased transcriptional arrest in vitro. J. Biol. Chem. 271: 6866-6873.

Prelich, G. and F. Winston. 1993. Mutations that suppress the deletion of an upstream activating sequence in yeast: involvement of a protein kinase and histone $\mathrm{H} 3$ in repressing transcription in vivo. Genetics 135: 665-676.

Reines, D. and J. Mote. 1993. Elongation factor SII-dependent transcription by RN A polymerase II through a sequence-specific DNA-binding protein. Proc. Natl. Acad. Sci. 90: 19171921. 
Rose, M., P. N ovick, J. Thomas, D. Botstein, and G. Fink. 1987. A Saccharomyces cerevisiae genomic plasmid bank based on a centromere-containing shuttle vector. Gene 60: 237-243.

Rose, M.D., F. Winston, and P. Hieter. 1990. Methods in yeast genetics: A laboratory course manual. Cold Spring Harbor Laboratory Press, Cold Spring Harbor, NY.

Scafe, C., C. Martin, M. N onet, S. Podos, S. Okamura, and R.A. Young. 1990a. Conditional mutations occur predominantly in highly conserved residues of RN A polymerase II subunits. Mol. Cell. Biol. 10: 1270-1275.

Scafe, C., M. N onet, and R.A. Young. 1990b. RN A polymerasell mutants defective in transcription of a subset of genes. Mol. Cell. Biol. 10: 1010-1016.

Sikorski, R.S. and P. Hieter. 1989. A system of shuttle vectors and yeast host strains designed for efficient manipulation of DNA in Saccharomyces cerevisiae. Genetics 122: 19-27.

Som, T., K.A. Armstrong, F.C. Volkert, and J.R. Broach. 1988. Autoregulation of $2 \mu \mathrm{m}$ circle gene expression provides a model for maintenance of stable plasmid copy levels. Cell 52: 27-37.

Stachora, A.A., R.E. Schäfer, M. Pohlmeier, G. Maier, and H. Ponsting. 1997. Human Supt5h protein, a putative modulator of chromatin structure, is reversibly phosphorylated in mitosis. FEBS Lett. 409: 74-78.

Swanson, M.S. and F. Winston. 1992. SPT4, SPT5, and SPT6 interactions: Effects on transcription and viability in Saccharomyces cerevisiae. Genetics 132: 325-336.

Swanson, M.S., E.A. Malone, and F. Winston. 1991. SPT5, an essential gene important for normal transcription in Saccharomyces cerevisiae, encodes an acidic nuclear protein with a carboxy-terminal repeat. Mol. Cell. Biol. 11: 3009-3019.

Thompson, N.E., T.H. Steinberg, D.B. Aronson, and R.R. Burgess. 1989. Inhibition of in vivo and in vitro transcription by monoclonal antibodies prepared against wheat germ RNA polymerase II that react with the heptapeptide repeat of eukaryotic RNA polymerase II. J. Biol. Chem. 264: 1151111520.

Uptain, S.M., C.M. Kane, and M.J. Chamberlin. 1997. Basic mechanisms of transcript elongation and its regulation. Annu. Rev. Biochem. 66: 117-172.

Wada, T., T. Takagi, Y. Yamaguchi, A. Ferdous, T. Imai, S. Hirose, S. Sugimoto, K. Yano, G.A. Hartzog, F. Winston et al. 1998. DSIF, a novel transcription el ongation factor that regulates RN A polymerase II processivity, is composed of human Spt4 and Spt4 homologs. Genes \& Dev. (this issue).

Winston, F. and M. Carlson. 1992. Yeast Snf/Swi transcriptional activators and the Spt/Sin chromatin connection. Trends Genet. 8: 387-391.

Winston, F., D.T. Chal eff, B. Valent, and G.R. Fink. 1984. Mutations affecting Ty-mediated expression of the HIS4 gene of Saccharomyces cerevisiae. Genetics 107: 179-197.

Winston, F., C. Dollard, and S.L. Ricupero-Hovasse. 1995. Construction of a set of convenient S. cerevisiae strains that are isogenic to S288C. Yeast 11: 53-55.

Wu, J., D.E. Awrey, A.M. Edwards, J. Archambault, and J.D. Friesen. 1996. In vitro characterization of mutant yeast RN A polymerase II with reduced binding for elongation factor TFIIS. Proc. Natl. Acad. Sci. 93: 11552-11557. 


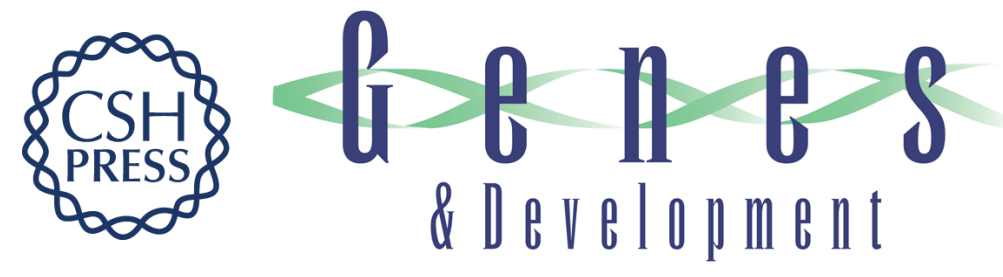

\section{Evidence that Spt4, Spt5, and Spt6 control transcription elongation by RNA polymerase II in Saccharomyces cerevisiae}

Grant A. Hartzog, Tadashi Wada, Hiroshi Handa, et al.

Genes Dev. 1998, 12:

References This article cites 46 articles, 30 of which can be accessed free at:

http://genesdev.cshlp.org/content/12/3/357.full.html\#ref-list-1

License

Email Alerting Receive free email alerts when new articles cite this article - sign up in the box at the top Service right corner of the article or click here.

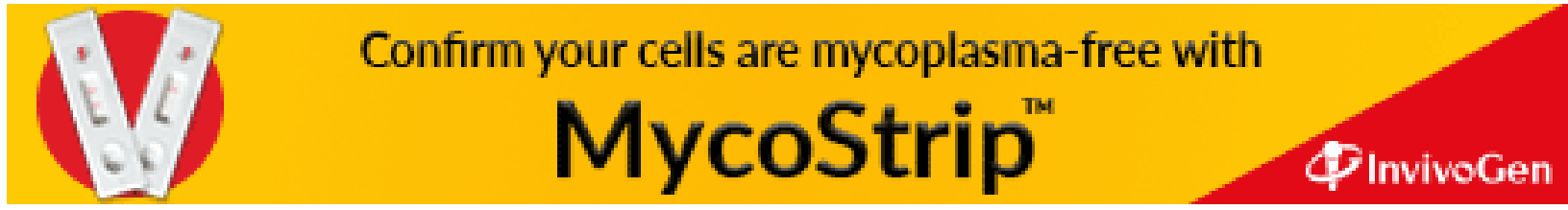

